\title{
Computation of Q3D Viscous Flows in Various Annular Turbine Stages with Heat Transfer
}

\author{
E.Y.K. $\mathrm{NG}^{\mathrm{a}, *}$ and MIAO $\mathrm{YI}^{\mathrm{b}}$ \\ a School of Mechanical and Production Engineering, Nanyang Technological University, Nanyang Avenue, Singapore 639798; \\ ${ }^{\mathrm{b}}$ Assembly Dept., National Semiconductor, 11, Lorong 3, Toa Payoh, Singapore 319579
}

(Received 8 May 1997; In final form 18 May 1997)

\begin{abstract}
A better understanding of the flow inside the multi-stage turbomachines will be very useful to both the designer and operator. The numerical calculation for single blade row has been well established with the time marching computation of the Navier-Stokes equations. But there will exist much more difficulties for the multi-blade rows due to the rotor-stator interaction. The major problems are related to the unsteady flow which will inevitably exist in the blade passages due to the different rotating speed and possible the different in blade number. A method is presented for simulating various turbine blade rows in single-stage environment. A solver has been developed for studying the complex flow analysis of 'proposed high pressure turbine' (HPT) using quasi-3-D Reynolds-averaged Navier-Stokes (Q3D RNS) equations. The code achieves good quality solutions quickly even with relatively coarse mesh sizes. The work is first validated both with UTRC's and Zeschky and Gallus' subsonic turbine test cases covering inlet boundary conditions and Reynolds-averaged values. A H-type grid is adopted as it is easy to generate and can readily extend to $3 \mathrm{D}$ application. When rows are closely spaced, there can be a strong interaction which will impact the aerodynamic, thermal and structural performance of the blade.
\end{abstract}

Keywords: Turbine stage, Mixing plane, Time marching, Navier-Stokes, Heat transfer, Viscous flow

\section{INTRODUCTION}

Many modern turbomachinery blade failures are attributed to high vibratory stresses arising from the interactions between rotating and stationary blade rows where the flow is very complex and often simplifying assumptions are needed to enable modeling to be more tractable. It is essential that the consequences of these assumptions are assumed by evaluation of models so that they can be used with confidence in their strengths and limitations to exploit design freedoms in practical applications. Many reports are available for single row calculation $(\mathrm{Ng}, 1996)$; but only few works on blade rows

*Corresponding author. Tel.: (65) 799-1453. Fax: (65) 791-1859. E-mail: mykng@ntu.edu.sg. 
calculation in multi-stage environment have been reported (for example: Arts, 1984; Koya et al., 1985; Denton, 1990; Rai, 1990).

As suggested by Denton and Singh (1979), the basic assumption is that the real unsteady flow experienced by the two blade rows in relative motion can be approximated by the steady flow obtained when the flow field at this axial station between the two rows is circumferentially averaged to avoid any possible inconsistent perturbation. Thus, the scope of the present paper is to explore how a single blade row Q3D RNS solver ( $\mathrm{Ng}$, 1994) could be deployed in a machine environment to provide useful and cost effective tools in a deeper understanding of the flow mechanism of loss production and of turning. This will be followed by a detailed description of the numerical procedure and the current capabilities of the solver are assessed by comparing the numerical results with high quality data from well-documented experiment by Gallus et al. (1995) and Dring et al. (1982) of the flows for subsonic turbine stages respectively. The code is further being used on 'proposed HPT' with real flow conditions and heat transfer prediction.

\section{NUMERICAL PROCEDURE}

The 2-D RNS equations are expressed in time marching finite volume form and cast in the bladerelative frame as

$$
\begin{array}{r}
\frac{\Delta(\mathrm{Vol})}{\Delta t}\left(\begin{array}{c}
\rho \\
\rho u \\
\rho v
\end{array}\right) \\
=\Delta y\left(\begin{array}{c}
\rho u \\
\rho u^{2}+p-\tau_{x x} \\
\rho u v-\tau_{x y}
\end{array}\right)_{\mathrm{I}}+\Delta x\left(\begin{array}{c}
\rho v \\
\rho u v-\tau_{x y} \\
\rho v^{2}+p-\tau_{y y}
\end{array}\right)_{\mathrm{J}} \\
-\Delta y\left(\begin{array}{c}
\rho v \\
\rho u^{2}+p-\tau_{x x} \\
\rho u v-\tau_{x y}
\end{array}\right)_{\mathrm{K}}-\Delta x\left(\begin{array}{c}
\rho u v-\tau_{x y} \\
\rho v^{2}+p-\tau_{y y}
\end{array}\right)_{\mathrm{L}}
\end{array}
$$

where the subscripts I, K and $\mathrm{J}, \mathrm{L}$ denote the cell face numbers in the pitchwise and streamwise directions respectively.

$\tau_{i, j}=2 \mu \frac{\partial u_{i}}{\partial x_{j}}-\frac{2}{3} \mu \frac{\partial u_{j}}{\partial x_{i}}$ when $i=j$

$\tau_{i, j}=\mu\left(\frac{\partial u_{i}}{\partial x_{j}}+\frac{\partial u_{j}}{\partial x_{i}}\right) \quad$ when $i \neq j, \mu=\left(1+\mu_{\mathrm{T}}\right) / \operatorname{Re}$.

Conservation of rothalpy with source term $(-2 \rho \Omega v)$ due to Coriolis force, across the blade row is used to reduce the computational work which is a common practice in turbomachinery flow. The equation of state is

$$
p=\frac{\gamma-1}{\gamma} \rho\left(h_{0}-\frac{u^{2}+v^{2}}{2}\right),
$$

with $h_{0}$ the constant stagnation enthalpy. The time marching compressible code remains "standard" for single row prediction as described in $\mathrm{Ng}$ (1994). The computational procedure for inter-mixing plane is based on the method suggested by Arts (1984). The Baldwin-Lomax (1978) zero equation model (BLM) was used for turbulent model. An artificial dissipation based on the work of Jameson (1984) is applied to add stability of the scheme and to capture flow discontinuities correctly in the viscous flow. In Q3D calculation, the spanwise variation of stream surface thickness is neglected, this could have a large effect on the solution. Q3D fails to predict the radial, tip leakage and strong secondary flows especially with high tip to hub ratio machines.

\section{MIXING PLANE MODEL AND BOUNDARY CONDITIONS}

The number of blades from blade row to blade row is generally not equal. The pitch used for each computation thus varied accordingly. This requires a careful modeling of the flow field communication between the blade rows. The two neighboring rows share common axial co-ordinates. The mixing planes are located approximately midway between two adjacent blade rows. The mixing plane is very 
close to the trailing edge of the upstream blades and leading edge of the downstream blades. The calculated values of each blade are values relative to its own frame of reference. In order to average out the mixing plane, transformation of these relative values from one blade row to adjacent blade row during area averaging processing is performed. The 'appropriate' assumed data will be given temporarily and at last it will be corrected by the calculation eventually. The following relations for stator/rotor configuration are used:

$$
M_{2 \mathrm{~A}}=\left[\sqrt{\frac{\left(W_{\theta \mathrm{R}}+r \Omega\right)^{2}+W_{x \mathrm{~A}}^{2}}{\gamma p / \rho}}\right]_{\text {Inlet Rotor }},
$$

$T_{02 \mathrm{R}}=$

$\left(\frac{\gamma-1}{\gamma} \frac{\rho E_{\mathrm{A}}+p+\rho\left(r^{2} \Omega^{2} / 2-r \Omega W_{\theta \mathrm{A}}\right)}{R_{\mathrm{g}} \rho}\right)_{\text {Outlet Stator }}$,

$$
\begin{aligned}
& p_{02 \mathrm{R}}=\left[p\left(\frac{R T_{02 \mathrm{R}}}{p / \rho}\right)^{\gamma /(\gamma-1)}\right]_{\text {Outlet Stator }}, \\
& \beta_{2}=\left[\tan ^{-1}\left(\frac{W_{\theta \mathrm{A}}-\Omega r}{W_{x \mathrm{~A}}}\right)\right]_{\text {Outlet Stator }},
\end{aligned}
$$

where $E$ is the total energy $\left(C_{v} T+W^{2} / 2\right) ; r$ is radial distance; $\gamma$ is the ratio of specific heats; $\Omega$ is the angular velocity of blades $(\mathrm{rad} / \mathrm{s}) ; \rho$ is the density; $R_{\mathrm{g}}$ is the gas constant. Subscripts $x, \theta, 0,1$, 2, 3, $\mathrm{A}$ and $\mathrm{R}$ are axial, pitchwise co-ordinate indices, total condition, inlet of the stage, outlet of stator, inlet of rotor, outlet of stage, absolute and relative values respectively.

First, guess the exit static pressure for upstream field (stator). Then calculate the upstream field by using the known parameters on the inlet of the whole stage and guessed parameter as the field outlet boundary condition. After the specified steps of the upstream field calculation, extrapolate the parameters in the relative frame on the mixing plane, such as total pressure, total temperature, velocities, flow angles, etc. Now using these parameters as inlet boundary conditions, calculate the downstream field (rotor). After the specified steps of downstream row calculation, the flow field in both up and downstream are obtained. Finally judge the correctness of the guessed parameter on the mixing plane by the flow situation in both the flow fields. The procedure is implemented and does not require any human intervention.

The boundary condition treatment is similar to that of a single blade row calculation except at mixing plane. Basically the boundary conditions include inlet, exit, solid surface and periodic boundary conditions. The periodic conditions are imposed on the blade-to-blade upstream of the leading edge and downstream of trailing edge to ensure the circumferential periodicity of the cascade. The total pressure, the total temperature and two flow angles are to be specified at the inlet boundaries for stator/rotor respectively. Outlet boundary condition is one of the most crucial condition to specify for the static pressure. The stator flow is considered in absolute co-ordinate system and rotor flow considered in relative coordinate system fixed to rotating blade. The flow variables at the downstream end of the stator are obtained by equating to those of rotor inlet located at the same axial position and the values at the upstream end of the rotor are obtained from those of stator outlet. The numerical boundary conditions described before include these two sets of interrow physical boundary conditions and their derivation are given in the Appendix.

\section{SAMPLE APPLICATIONS: SINGLE-STAGE AXIAL TURBINES}

A sample of results is presented in this paper for various turbine geometries. The first experimental data were obtained in a subsonic axial-flow turbine stage with untwisted blades of Technical University Aachen, Germany, and were fully reported by Gallus et al. (1995). In the stator, the 'Traupel' profile was used whereas the rotor consists of modified VKI-profiles. All experimental data is normalised with respect to the International 
Standard Atmosphere at stator inlet and refers to the design operation point of the turbine. The data can improve the understanding of the more complex flow in modern, multi-stage turbines. A cross section of the stage with midspan velocity triangles is shown in Fig. 1.

The $(72 \times 29)+(72 \times 39)$ finite volume H-mesh was used as illustrated in Fig. 2. The grid is refined exponentially near blade suction and pressure surfaces and in the axial direction cells are concentrated near the leading and trailing edges. Also, the solution domain extends a distance of half the axial chord upstream and downstream of the stage. With this grid, a flow field prediction was achieved in about $(16 \times 800)$ time steps and the code run at about $3.8 \times 10^{-4} \mathrm{~s}$ per point per time step on a Vax-9000.

\section{Rotor Flow: Surface Pressure Distributions}

A comparison between rotor midspan surface pressure measurements and computations is shown

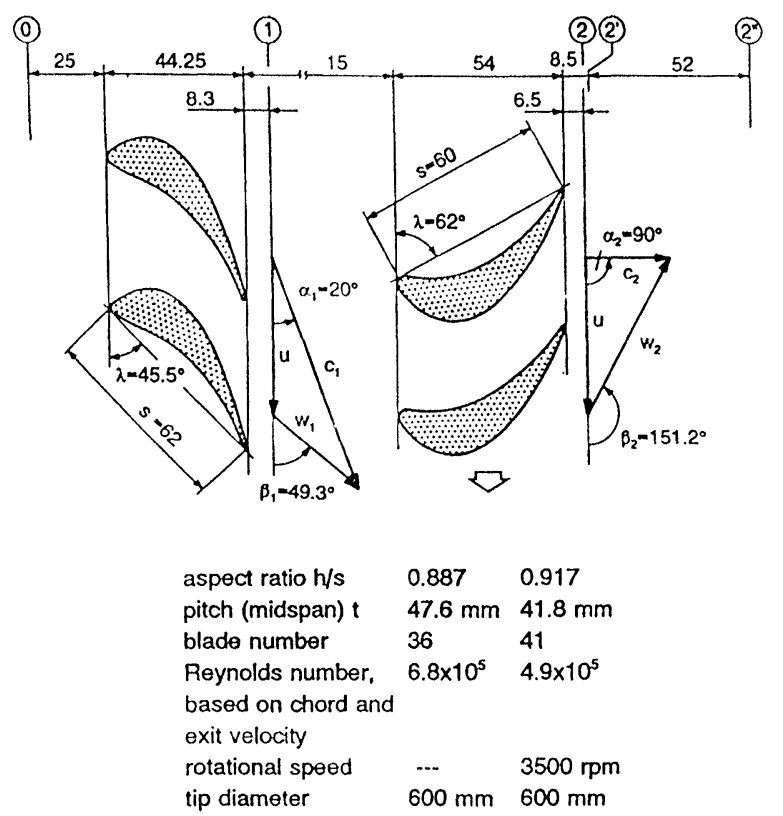

FIGURE 1 Turbine design data taken from Gallus et al. (1995). in Fig. 3. Here the data are illustrated in the form of a pressure coefficient which is calculated from the local static and inlet total pressures and are plotted against axial chord $C_{x}$. At the pressure side, the static pressure is nearly constant up to $40 \%$ axial

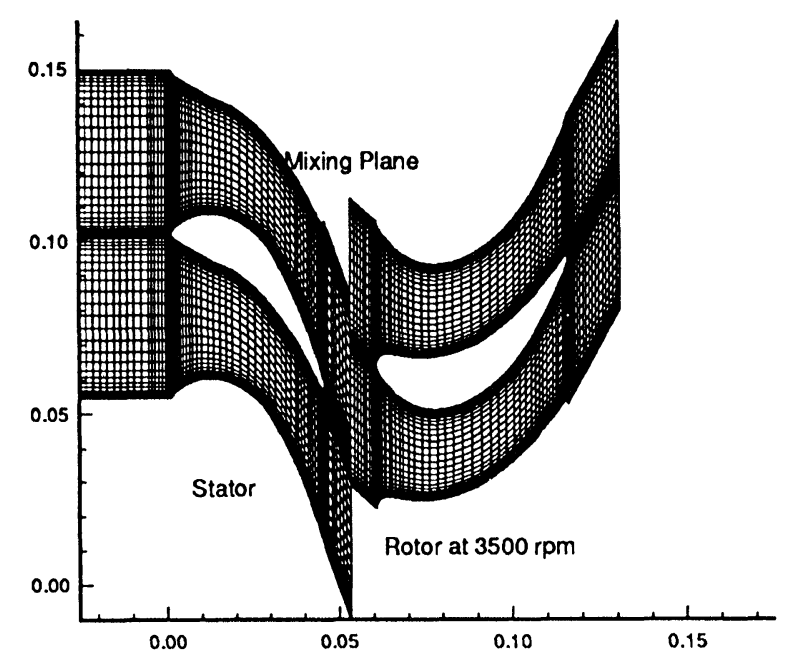

FIGURE 2 Computational H-grid system for Gallus' LPT stage.

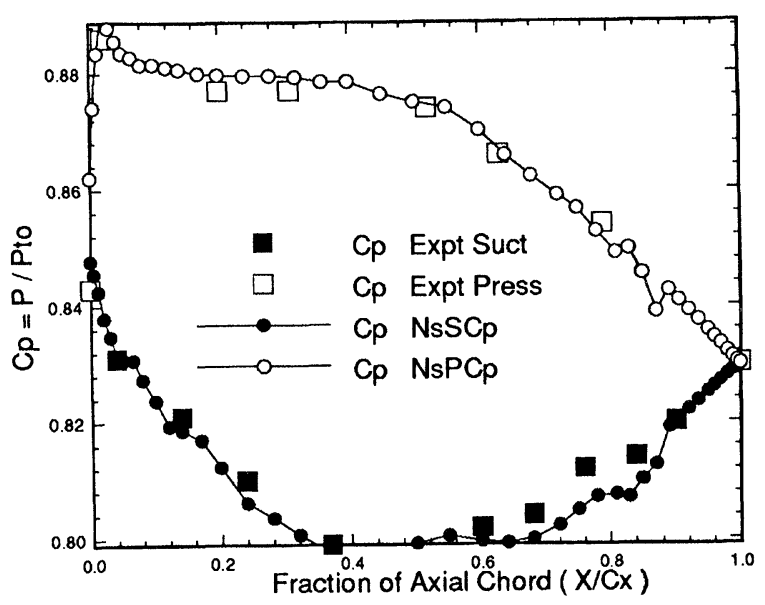

FIGURE 3 Comparison of $C_{p}$ vs $X / C_{x}$ for Gallus' LPT rotor. 
chord, followed by an acceleration in the last part of the passage. Some discrepancies are apparent for the region near trailing edge on the suction surface, this is a region of closed separation and may be due to shortcomings of the turbulence model in the transition zone.

\section{Complete Stage Prediction}

Figure 4 contains the prediction of total, static pressure, Mach number contours and velocity vector plots. Mach number contours are shown with a full 3D NS calculation taken from Chen et al. (1995) and the agreement is considered satisfactory. As the gap spacing between the rotor and stator is very small (only $15 \mathrm{~mm}$ ), turbulent flow will exist in the rotor. However, the whole flow fields in both the rotor and stator are general smooth, steady and varied regularly. Thus, generally, the result is very encouraging and qualitatively correct as expected though no detailed experimental data is available for comparison.

Many CFD researchers used UTRC test case by Dring et al. (1982) to verify their computational algorithm. Figures 5 and 6 show the predicted iso-Mach contour with $(2 \times(42 \times 35)) \mathrm{H}$-mesh and the comparison of pressure coefficient distribution for the UTRC's LPT stator/rotor blades. Figure 7 shows heat transfer comparisons at design Reynolds number at $\phi$ (ratio of axial velocity to mean blade speed) value of 0.78 .

The agreement on the suction surfaces in particular for the rotor are deteriorated as the degree of agreement between the calculation and the Dring's experimental data is primarily determined by the choice of model for transition with effect of free-stream turbulence. No transition model is used in the current code and the flow is assumed turbulent throughout the passage without taking account for the level of free stream turbulence. Whereas, the rotor, being behind the stator, is often in a high turbulence environment.

Finally, the solver is further being used on the 'proposed HPT'. A combination of design infor- mation and measured data for this 'proposed HPT' has been used to define the boundary conditions. The geometry of midspan stator and rotor blades and the grid configurations are shown in Fig. 8. The dimensional data of the blades are listed in Table I together with the relevant flow data used for the calculation.

The current simulation assumes the flow to be fully turbulent from the leading edge of the upstream row blade. The boundary layer is thickening as we move from leading edges to the trailing edges of the stator and rotor. Moreover pressure contours varied regularly. Figures 9 and 10 show the static Isobar plot and convergence history. The solution converged within $(12 \times$ $(800+1000))$ time steps using $(2 \times(86 \times 45)) \mathrm{H}$ mesh. The residual of the continuity equation is used as convergence criteria (up to mass error less than $1 \%$ ) and this is obtained by using an IBM work station RISC-6000.

The current analysis can also be used to predict turbine heat transfer reasonably well. The NS analysis have the ability to calculate the heat transfer even with a flow separation. Figure 11 shows the predicted Stanton numbers $(\mathrm{St}=$ $\left.k|\partial T / \partial y|_{\mathrm{w}} /\left[(\rho u)_{\mathrm{in}} C_{p}\left(T_{\mathrm{in}}^{\prime}-T_{\mathrm{w}}\right)\right]\right)$ for stator/rotor of 'proposed HPT'. Higher order of turbulence model together with transition criterion should be used to obtain a better heat transfer rate calculation.

\section{CONCLUDING REMARKS}

Sample calculation of the current Q3D RNS solver has been outlined for various axial flow complete turbine stages, with emphasis on viscous effect. The code can also be applied to investigate other types of axial machines such as compressor and pump. Some numerical errors in regions of very high gradients, such as the leading edge together with $\mathrm{H}$-grid, are to be expected. The effect of these errors, however, is local and the gross features of the flow are correctly predicted. 


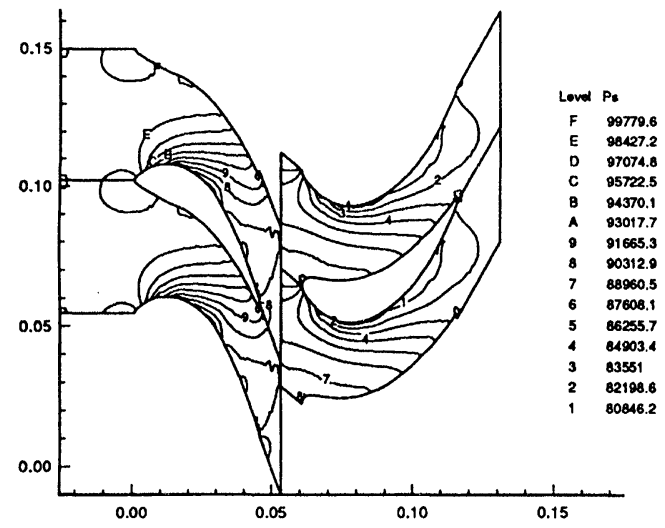

(a)

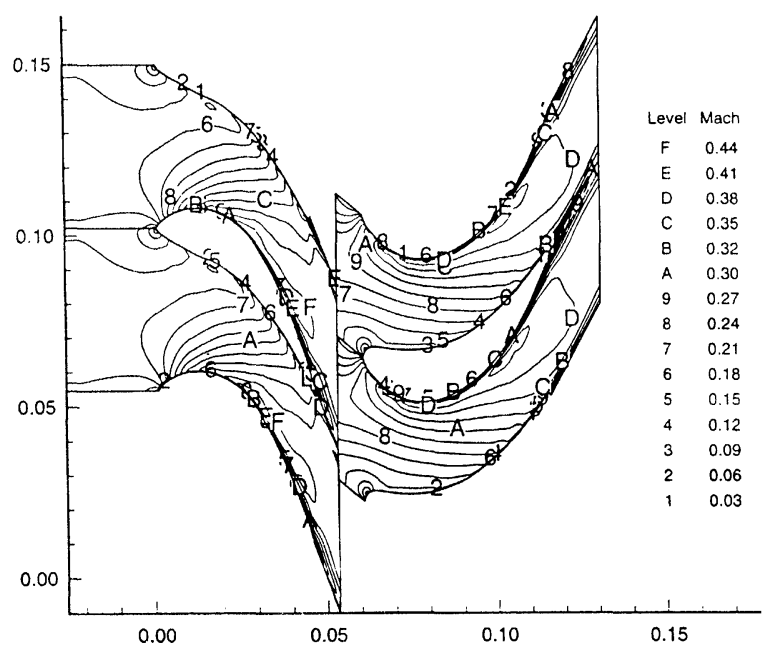

(c)

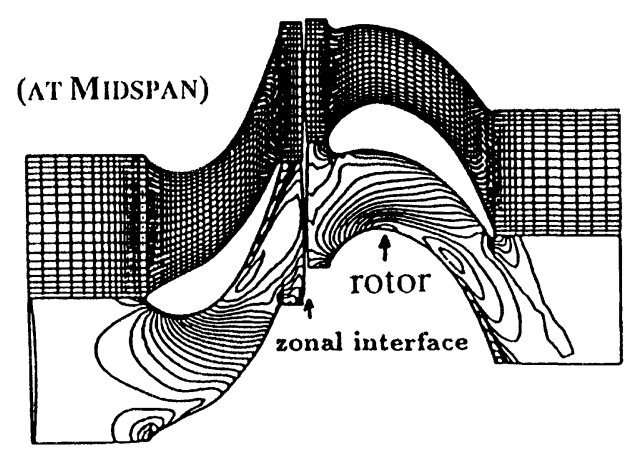

(d)

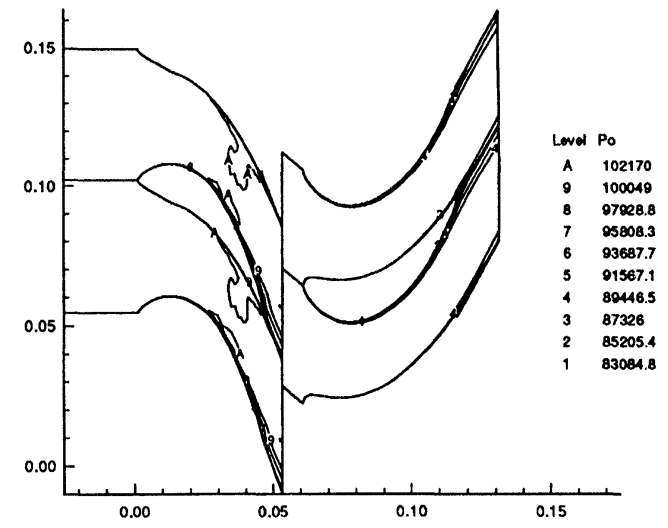

(b)

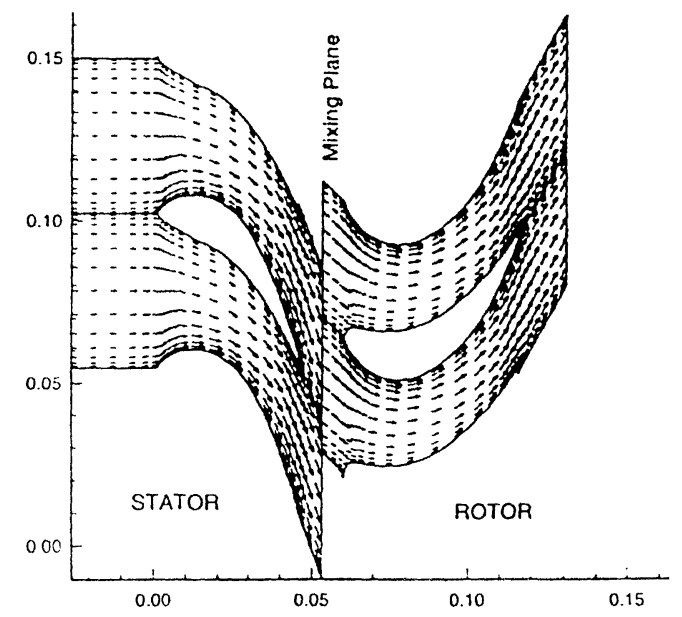

(e)

FIGURE 4 Complete-stage calculation for Gallus' LPT: (a) static isobar contour; (b) total isobar contour; (c) current predicted iso-Mach contour; (d) predicted iso-Mach contour by Chen et al. (1995); (e) velocity vector plot. 


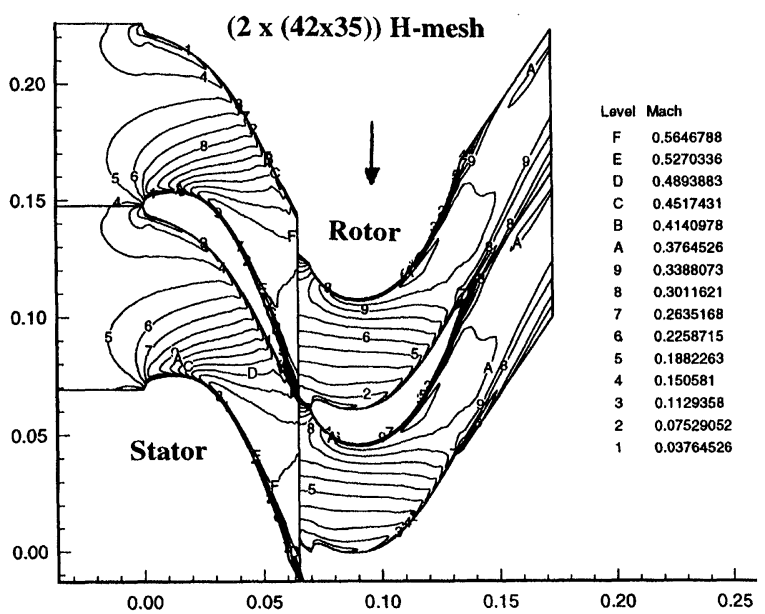

FIGURE 5 Predicted Iso-Mach contour for the UTRC LPT stator/rotor blades $(2 \times(42 \times 35)) \mathrm{H}$-mesh.

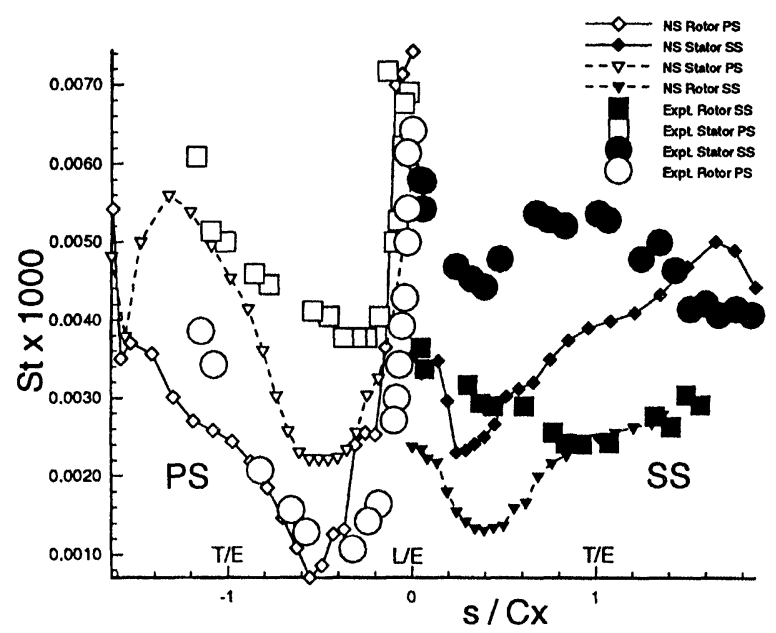

FIGURE 7 Comparison of Stanton numbers for stator/rotor of Dring's UTRC LPT.
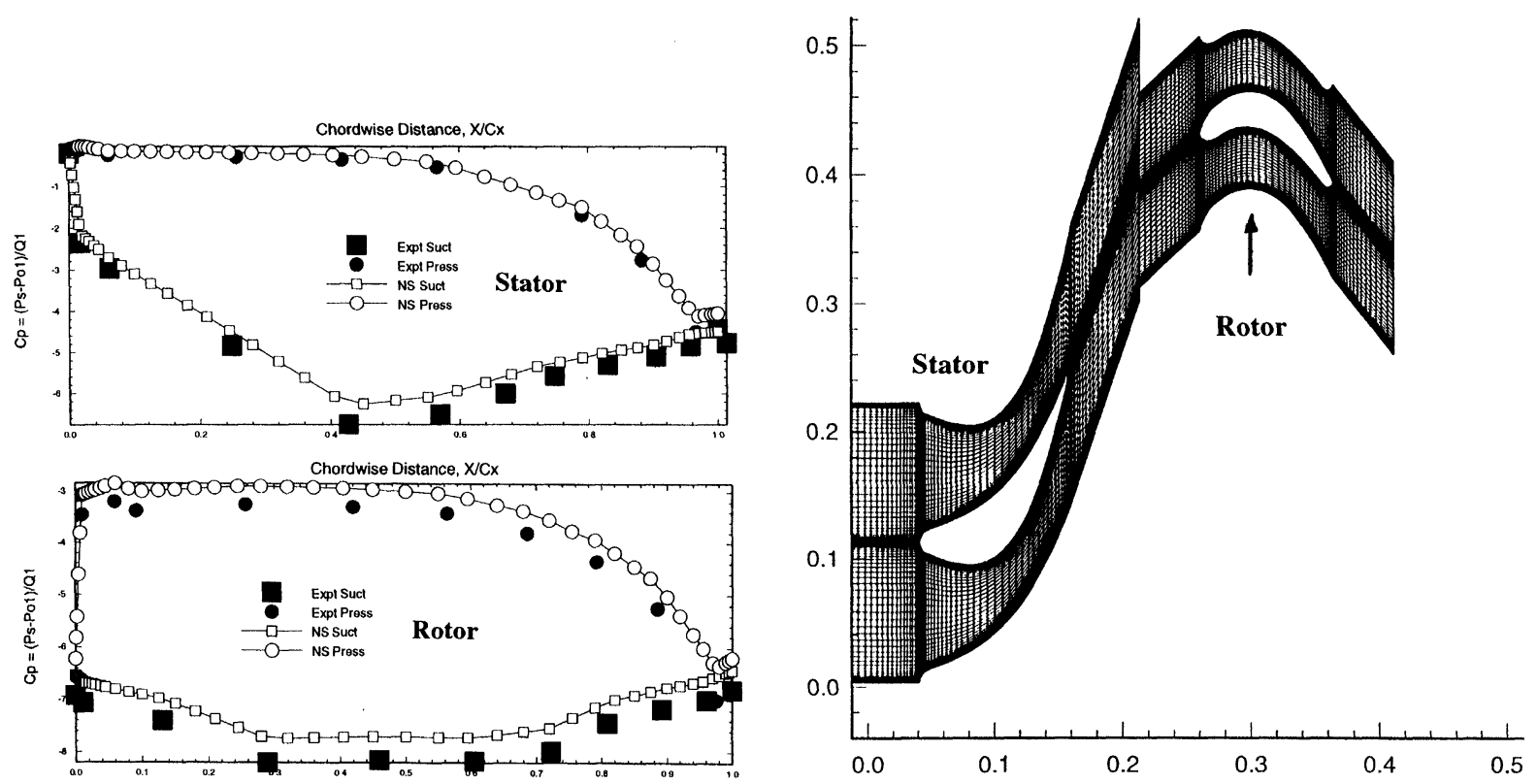

FIGURE 6 Comparison of pressure coefficient distribution for the UTRC LPT stator/rotor blades.

FIGURE 8 Computational mesh $(2 \times(86 \times 45))$ used for 'proposed HPT'. 
TABLE I Dimensional and relevant flow data of the HPT blades

\begin{tabular}{|c|c|c|c|c|}
\hline \multirow[t]{2}{*}{ Characteristics } & \multicolumn{2}{|c|}{ Proposed turbine (HPT) } & \multicolumn{2}{|c|}{ UTRC turbine test case } \\
\hline & Rotor & Stator & Rotor & Stator \\
\hline Inlet Mach number & 0.207 & 0.1325 & 0.251 & 0.159 \\
\hline Exit Mach number & 0.9698 & 0.45 & 0.3788 & 0.4213 \\
\hline Inlet total temperature $(\mathrm{K})$ & 598.23 & 585.16 & 280.63 & 286.97 \\
\hline Inlet total pressure $\left(\mathrm{N} / \mathrm{m}^{2}\right)$ & 100402.0 & 817056.6 & $1.02 \times 10^{5}$ & $1.013 \times 10^{5}$ \\
\hline $\begin{array}{l}\text { Reynolds number (Based on axial } \\
\text { chord and isentropic exit) }\end{array}$ & $2.91 \times 10^{5}$ & 406757.0 & $5.5 \times 10^{5}$ & $5.9 \times 10^{5}$ \\
\hline Inlet angle (Deg) & 45.0 & 0.0 & -40.0 & 0.0 \\
\hline Exit angle (Deg) & -50.0 & 71.0 & 64.5 & -67.0 \\
\hline Rotation speed (RPM) & 5395.0 & 0.0 & 410.0 & 0.0 \\
\hline Pitch $(\mathrm{m})$ & 0.07523 & 0.10947 & 0.061557 & 0.0783456 \\
\hline Span (mm) & 40.2 & 40.2 & 152.4 & 152.4 \\
\hline Blade number & 64 & 44 & 28 & 22 \\
\hline Midspan radius (mm) & 255.42 & 255.42 & 685.8 & 685.8 \\
\hline Axial gap & \multicolumn{2}{|c|}{$87 \%$ of average chord length } & \multicolumn{2}{|c|}{$15 \%$ of average chord length } \\
\hline
\end{tabular}

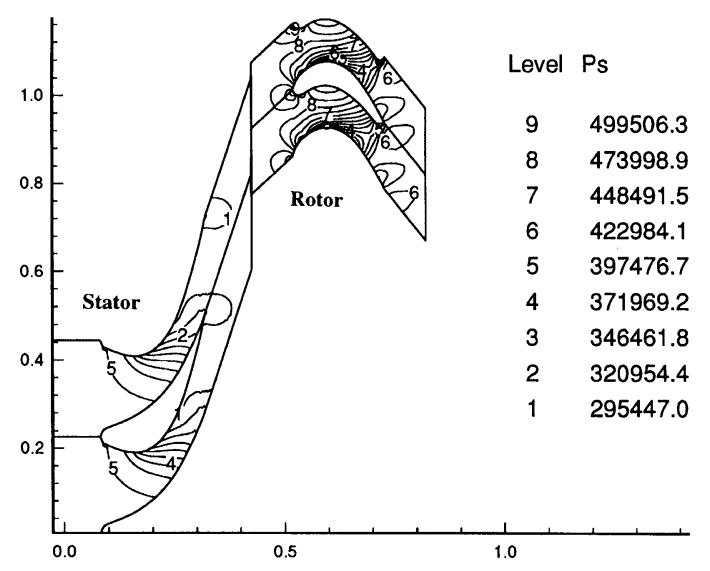

FIGURE 9 Static isobar plot for the 'proposed HPT'.

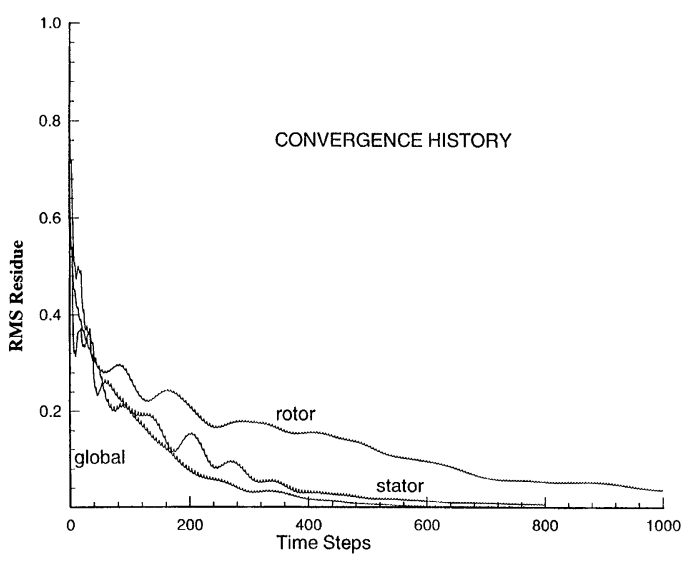

FIGURE 10 Convergence history for the 'proposed HPT'.

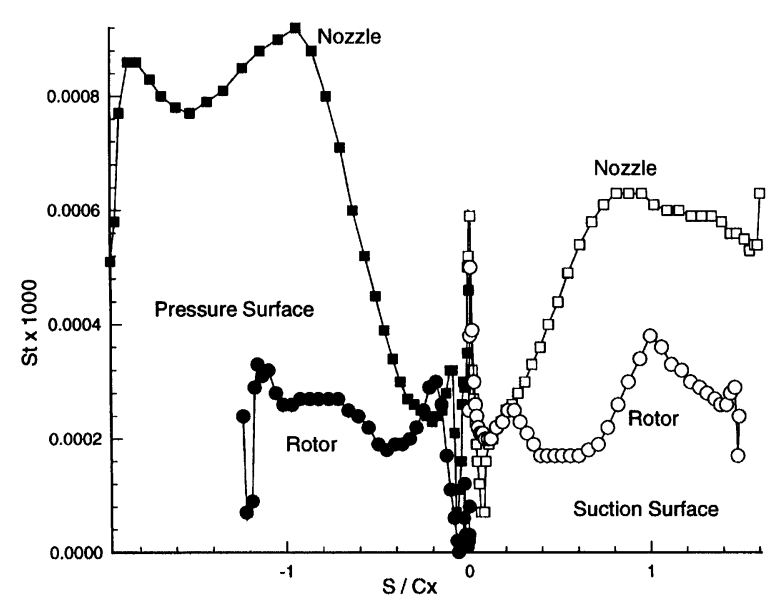

FIGURE 11 Predicted Stanton numbers for stator/rotor of 'proposed HPT'.

\section{References}

Arts, T., 1984. Calculation of 3D, steady inviscid flow in a transonic axial turbine stage, ASME paper 84-GT-76.

Baldwin, B.S. and Lomax, H., 1978. Thin layer approximation and algebraic model for separated turbulent flows, AIAA paper $78-257$.

Chen, N.X. and Zhang, F.X., 1995. An advance CFD simulation of 3D turbulent flow of a turbine stage, The 6th Asian Congress of Fluid Mechanics, Singapore.

Denton, J.D., 1990. The calculation of three dimensional viscous flow through multi-stage turbomachines, ASME paper 90-GT-19.

Denton, J.D. and Singh, U.K., 1979. Time Marching Methods for Turbomachinery Flow Calculation, VKI Lecture Series on Transonic Flows in Turbomachinery. 
Dring, R.P., Joslyn, H.D., Hardni, L.W. and Wagner, J.H., 1982. Turbine stage rotor-stator interaction, ASME J. of Engrg. Power, 104, 729-742.

Gallus, H.E., Zeschky, J. and Hah, C., 1995. Endwall and unsteady flow phenomena in an axial turbine stage, $A S M E J$. of Turbomachinery, 117, 562-570.

Jameson, A. and Baker, T.J., 1984. Multi-grid solution of the Euler equations for aircraft configurations, AIAA paper 840093.

Koya, M. and Kotake, S., 1985. Numerical analysis of fully 3-D periodic flows through a turbine stage, ASME J. of Engrg Gas Turbines and Power, 107, 945-952.

Ng, E.Y.K., 1994. Cascade flow calculations by a N-S Implicit F-V Method, CFD J., 3, 161-174.

Ng, E.Y.K. and Liu, S.Z., 1996. A novel implicit difference algorithm of primitive variable flow equations with higher order extra terms, International Journal of Computer \& Fluids, 26(2), 163-182.

Rai, M.M. and Madavan, N.K., 1990. Multi-airfoil NavierStokes solutions of turbine rotor-stator interactions, $A S M E$ J. of Turbomachinery, 117, 562-570.

\section{APPENDIX}

The original equations are

$$
\begin{gathered}
M_{2 \mathrm{~A}}=\frac{\left|W_{2 \mathrm{~A}}\right|}{\sqrt{\gamma R T_{2 \mathrm{~A}}}}, \quad T_{2 \mathrm{~A}}=T_{2 \mathrm{R}}, \\
\left|W_{2 \mathrm{~A}}\right|=\sqrt{W_{2 \theta \mathrm{A}}^{2}+W_{2 x \mathrm{~A}}^{2}} .
\end{gathered}
$$

As $W_{2 \theta \mathrm{A}}=W_{2 \theta \mathrm{R}}+r \Omega$ and $W_{2 x \mathrm{~A}}=W_{2 x \mathrm{R}}$, the equation should be

$$
M_{2 \mathrm{~A}}=\left[\sqrt{\frac{\left(W_{\theta \mathrm{R}}+r \Omega\right)^{2}+W_{x \mathrm{~A}}^{2}}{\gamma p / \rho}}\right]_{\text {Inlet Rotor }}
$$

For Eq. (2), using the velocity triangle, $W_{2 \theta \mathrm{A}}=$ $W_{2 \theta \mathrm{R}}+r \Omega \quad$ and $\quad E_{\mathrm{A}}=C_{v} T+0.5 W_{\mathrm{A}}^{2}, \quad E_{\mathrm{R}}=$ $C_{v} T+0.5 W_{\mathrm{R}}^{2}$ give: $E_{\mathrm{A}}=E_{\mathrm{R}}-0.5 \Omega^{2} r^{2}+r \Omega W_{\theta \mathrm{A}}$. As

$$
\begin{aligned}
& E_{\mathrm{R}}= C_{p} T_{02 \mathrm{R}}, \quad T_{\mathrm{A}}=T_{\mathrm{R}}, \quad W_{x \mathrm{~A}}=W_{x \mathrm{R}} \\
& \text { and } W_{\theta \mathrm{R}}^{2}=\left(W_{\theta \mathrm{A}}-r \Omega\right)^{2}, \\
& C_{p} T_{\mathrm{R}}+\frac{W_{\mathrm{R}}^{2}}{2}=C_{p} T_{\mathrm{A}}+\frac{\left(W_{\theta \mathrm{A}}-r \Omega\right)^{2}+W_{x \mathrm{~A}}^{2}}{2} \\
&=C_{p} T_{\mathrm{A}}+\frac{W_{\mathrm{A}}^{2}}{2}+\left(\frac{U^{2}}{2}-U W_{\theta \mathrm{A}}\right) .
\end{aligned}
$$

As

$$
C_{p}=\frac{\gamma}{\gamma-1} R=C_{v}+R_{\mathrm{g}}
$$

and

$$
C_{p} T_{0 \mathrm{R}}=C_{p} T_{\mathrm{R}}+\frac{W_{\mathrm{R}}^{2}}{2},
$$

we have

$$
\begin{aligned}
C_{p} T_{02 \mathrm{R}}= & C_{v} T_{\mathrm{A}}+R T_{\mathrm{A}}+\frac{W_{\mathrm{A}}^{2}}{2} \\
& +\left(\frac{U^{2}}{2}-U W_{\theta \mathrm{A}}\right) \\
= & C_{v} T_{\mathrm{A}}+\frac{p}{\rho}+\frac{W_{\mathrm{A}}^{2}}{2}+\left(\frac{U^{2}}{2}-U W_{\theta \mathrm{A}}\right), \\
\frac{\gamma}{\gamma-1} T_{02 \mathrm{R}}= & E_{\mathrm{A}}+\frac{p}{\rho}+\left(\frac{U^{2}}{2}-U W_{\theta \mathrm{A}}\right) .
\end{aligned}
$$

Hence

$T_{02 \mathrm{R}}=$

$\left(\frac{\gamma-1}{\gamma} \frac{\rho E_{\mathrm{A}}+p+\rho\left(\left(r^{2} \Omega^{2} / 2\right)-r \Omega W_{\theta \mathrm{A}}\right)}{R_{\mathrm{g}} \rho}\right)_{\text {Oulet Stator }}$

For Eq. 3, the original equation is the adiabatic process and the gas equations

$$
\frac{p}{\rho^{\gamma}}=\text { const. } \text { and } \quad \frac{p}{\rho T}=\text { const. }
$$

Lastly, Eq. (4) can be easily derived from the velocity triangle. 


\section{ait \\ ENERGY MATERIALS}

M A N E Y publishing

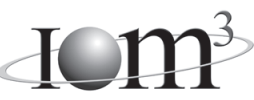

\section{Materials Science \& Engineering for Energy Systems}

Maney Publishing on behalf of the Institute of Materials, Minerals and Mining

The Institute of Materials, Minerals \& Mining

Economic and environmental factors are creating ever greater pressures for the efficient generation, transmission and use of energy. Materials developments are crucial to progress in all these areas: to innovation in design; to extending lifetime and maintenance intervals; and to successful operation in more demanding environments. Drawing together the broad community with interests in these areas, Energy Materials addresses materials needs in future energy generation, transmission, utilisation, conservation and storage. The journal covers thermal generation and gas turbines; renewable power (wind, wave, tidal, hydro, solar and geothermal); fuel cells (low and high temperature); materials issues relevant to biomass and biotechnology; nuclear power generation (fission and fusion); hydrogen generation and storage in the context of the 'hydrogen economy'; and the transmission and storage of the energy produced.

As well as publishing high-quality peer-reviewed research, Energy Materials promotes discussion of issues common to all sectors, through commissioned reviews and commentaries. The journal includes coverage of energy economics and policy, and broader social issues, since the political and legislative context influence research and investment decisions.

\section{CALL FOR PAPERS}

Contributions to the journal should be submitted online at http://ema.edmgr.com

To view the Notes for Contributors please visit: www.maney.co.uk/journals/notes/ema

Upon publication in 2006, this journal will be available via the Ingenta Connect journals service. To view free sample content online visit: www.ingentaconnect.com/content/maney

For further information please contact:

Maney Publishing UK

Tel: +44 (0)113 2497481 Fax: +44 (0)1132486983 Email: subscriptions@maney.co.uk

or

Maney Publishing North America

Tel (toll free): 8662975154 Fax: 6173546875 Email: maney@maneyusa.com

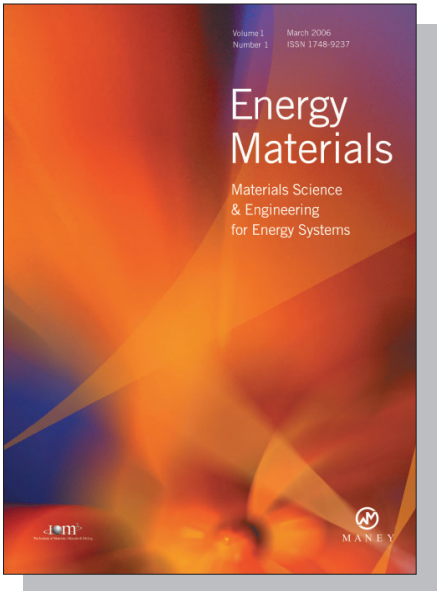

EDITORS

Dr Fujio Abe

NIMS, Japan

Dr John Hald, IPL-MPT, Technical University of Denmark, Denmark

Dr R Viswanathan, EPRI, USA

\section{SUBSCRIPTION INFORMATION}

Volume 1 (2006), 4 issues per year

Print ISSN: 1748-9237 Online ISSN: 1748-9245

Individual rate: $£ 76.00 / U S \$ 141.00$

Institutional rate: $£ 235.00 /$ US $\$ 435.00$

Online-only institutional rate: $£ 199.00 / U S \$ 367.00$

For special $\mathrm{IOM}^{3}$ member rates please email

subscriptions@maney.co.uk

\section{For further information or to subscribe online please visit www.maney.co.uk}



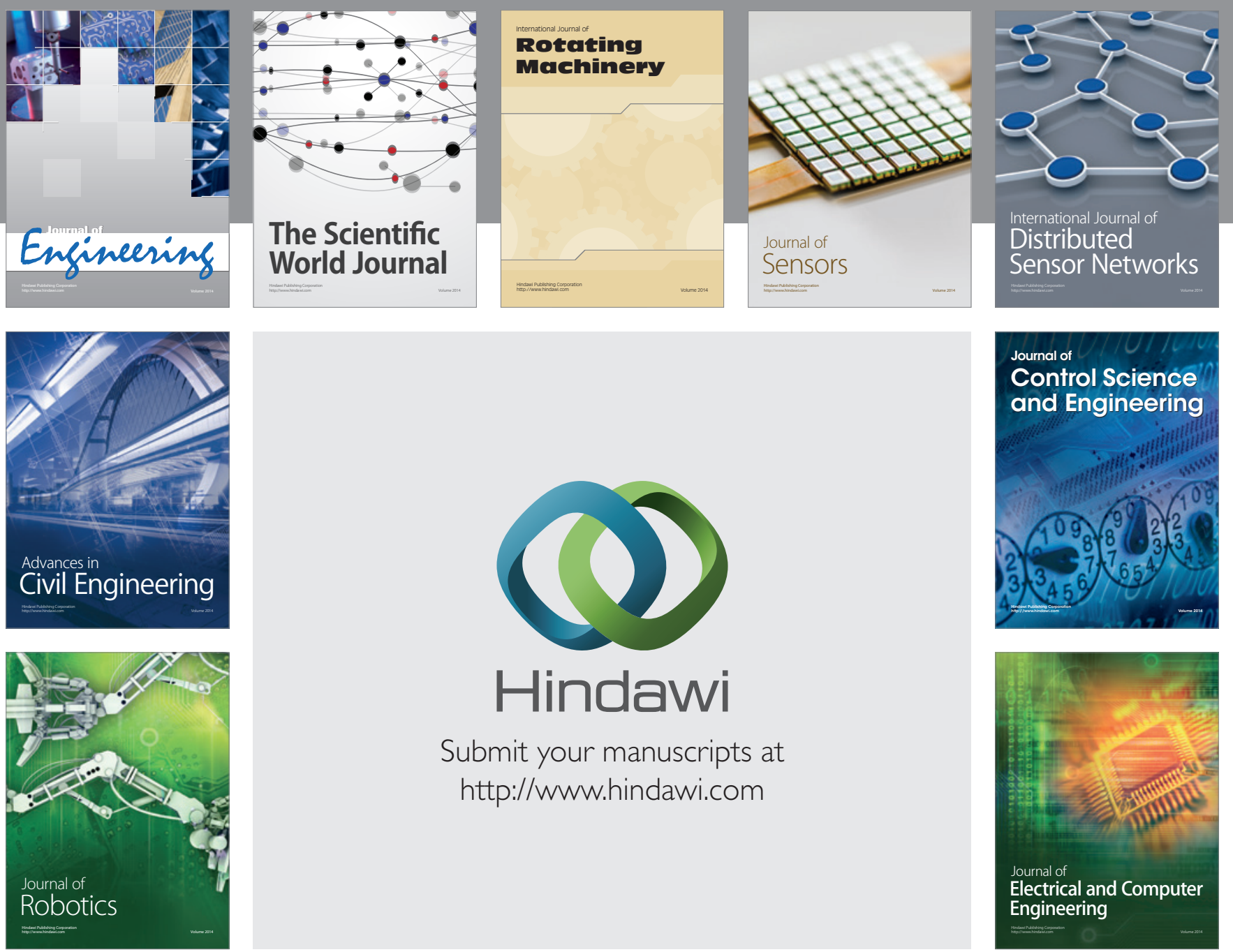

Submit your manuscripts at

http://www.hindawi.com
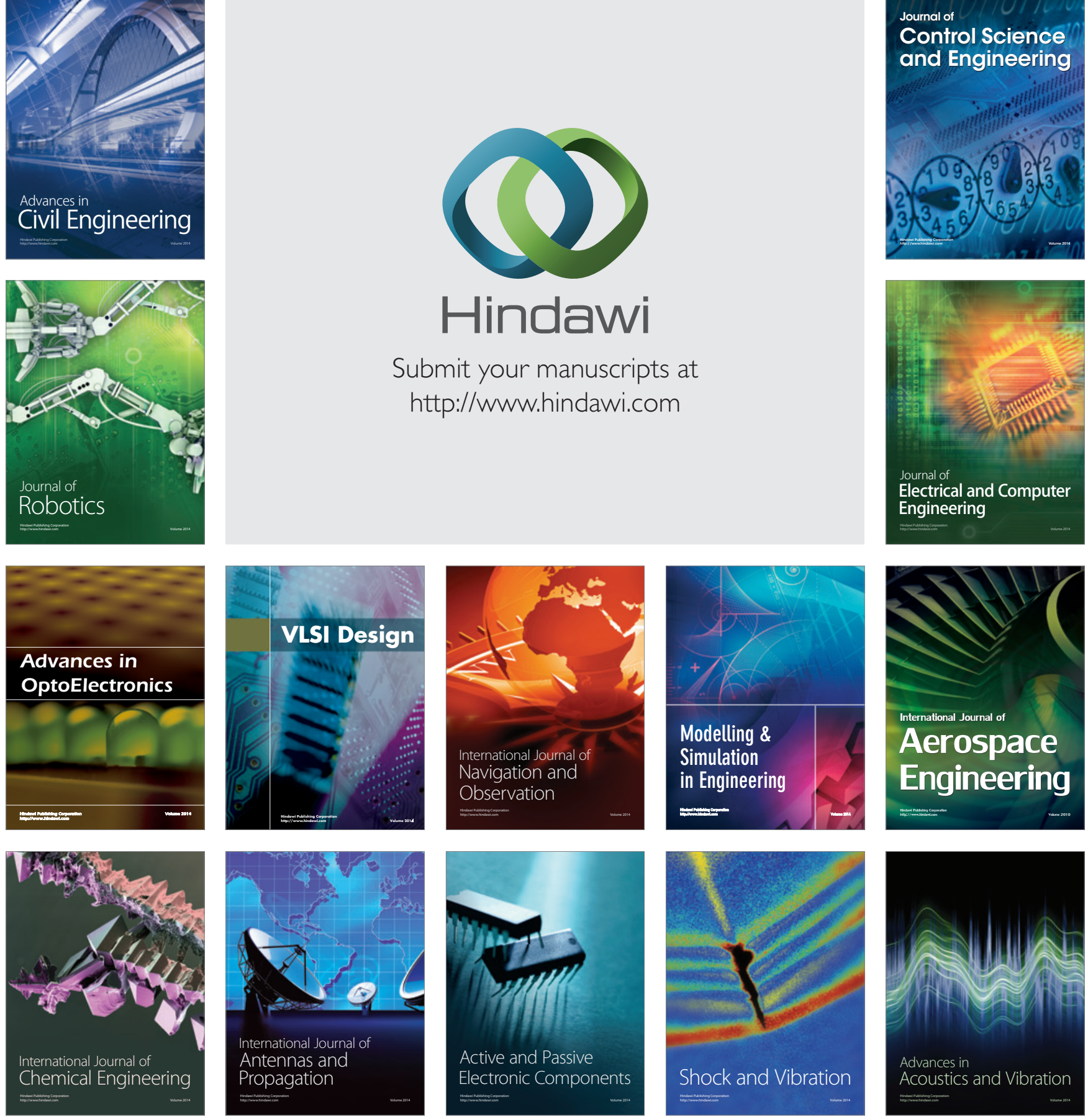